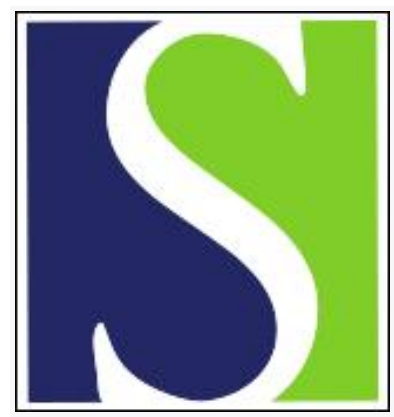

Scand J Work Environ Health 2017;43(2):146-154

https://doi.org/10.5271/sjweh.3620

Published online: 06 Jan 2017, Issue date: 01 Mar 2017

Joint association of multimorbidity and work ability with risk of long-term sickness absence: a prospective cohort study with register follow-up

by Sundstrup E, Jakobsen MD, Mortensen OS, Andersen LL

A higher number of chronic diseases - especially when considering combined back disorders and depression - are progressively associated with increased risk for long-term sickness absence. Importantly, good work ability appears to be a protective factor in spite of chronic disease. Workplace policies should secure maintenance of work ability among people with chronic diseases to ensure a long and sustainable work-life.

Affiliation: National Research Centre for the Working Environment, Lersø Parkallé 105, Copenhagen, Denmark. esu@nrcwe.dk

Refers to the following texts of the Journal: 2003;29(4):270-279

2009;35(1):1-5 2014;40(3):244-251

The following articles refer to this text: 2019;45(6):610-621;

2022;48(7):560-568

Key terms: association; back disorder; back pain; cancer; cardiovascular disease; chronic disease; cohort study; CVD; depression; diabetes; long-term sickness absence; multimorbidity; occupational health; occupational health; prospective cohort study; register follow-up; sickness absence; sickness absence; WAl; work ability; work ability index

This article in PubMed: www.ncbi.nlm.nih.gov/pubmed/28060994

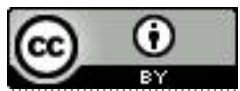




\title{
Joint association of multimorbidity and work ability with risk of long-term sickness absence: a prospective cohort study with register follow-up
}

\author{
by Emil Sundstrup, PhD, ${ }^{1}$ Markus Due Jakobsen, PhD, ${ }^{1}$ Ole Steen Mortensen, PhD, ${ }^{2}$ Lars Louis \\ Andersen, $P h D^{1,3}$
}

\begin{abstract}
Sundstrup E, Jakobsen MD, Mortensen OS, Andersen LA. Joint association of multimorbidity and work ability with risk of long-term sickness absence: a prospective cohort study with register follow-up. Scand J Work Environ Health. 2017;43(2):146-154. doi:10.5271/sjweh.3620
\end{abstract}

\begin{abstract}
Objectives The aim of this study was to determine the joint association of multimorbidity and work ability with the risk of long-term sickness absence (LTSA) in the general working population.

Methods Cox regression analysis censoring for competing events (statutory retirement, early retirement, disability pension, immigration, or death) was performed to estimate the joint association of chronic diseases and work ability in relation to physical and mental demands of the job with the prospective risk for LTSA (defined as $\geq 6$ consecutive weeks during 2-year follow-up) among 10427 wage earners from the general working population (2010 Danish Work Environment Cohort Study). Control variables were age, gender, psychosocial work environment, smoking, leisure physical activity, body mass index, job group, and previous LTSA.
\end{abstract}

Results Of the 10427 respondents, $56.8 \%$ had experienced $\geq 1$ chronic disease at baseline. The fully adjusted model showed an association between number of chronic diseases and risk of LTSA. This association was stronger among employees with poor work ability (either physical or mental). Compared to employees with no diseases and good physical work ability, the risk estimate for LTSA was 1.95 [95\% confidence interval $(95 \% \mathrm{CI})$ $1.50-2.52$ ] for employees with $\geq 3$ chronic diseases and good physical work ability, whereas it was $3.60(95 \%$ CI 2.50-5.19) for those with $\geq 3$ chronic diseases and poor physical work ability. Overall, the joint association of chronic disease and work ability with LTSA appears to be additive.

Conclusions Poor work ability combined with $\geq 1$ chronic diseases is associated with high risk of long-term sickness absence in the general working population. Initiatives to improve or maintain work ability should be highly prioritized to secure sustainable employability among workers with $\geq 1$ chronic diseases.

Key terms back disorder; back pain; cancer; cardiovascular disease; CVD; chronic disease; diabetes; depression; occupational health; WAI; work ability index.

During recent years, the number of people with one or more chronic diseases has increased. This is likely due to unhealthy lifestyle and improved treatment, increasing survival rates of individuals with a chronic disease (1). In Denmark, $34.9 \%$ of the adult population report having at least one chronic disease and the prevalence increases with age (2). As the elderly accounts for an increasing proportion of the total population in most western societies, the age of the general workforce is rising $(3,4)$. Because of the strong association between chronic disease and age $(2,5)$, the proportion of workers with poor health is growing. Specifically, the prevalence of chronic disease in the Danish working population has increased from $25.1 \%$ in 2010 to $26.8 \%$ in 2013 and is expected to increase even further in future years $(2,6)$. Thus, research that can help to identify and improve health behavior early in working life (7) could potentially help reduce development of future diseases and thereby prevent premature exit from the labor market.

The coexistence of several chronic diseases - ie, multimorbidity - frequently occurs, especially in the elderly population (8). For instance, $43 \%$ of Americans with a chronic medical condition have multimorbidity and studies from Australia have reported that $80 \%$ of the population aged $\geq 65$ years have $\geq 3$ chronic conditions (9-11). Multimorbidity has been associated with

1 National Research Centre for the Working Environment, Copenhagen, Denmark.

2 Department of Occupational Medicine, Holbæk Hospital, Denmark.

3 Physical Activity and Human Performance group, SMI, Department of Health Science and Technology, Aalborg University, Denmark.

Correspondence to: Emil Sundstrup, National Research Centre for the Working Environment, Lersø Parkallé 105, Copenhagen, Denmark. [E-mail: esu@nrcwe.dk] 
a decline in many health outcomes - such as quality of life, mobility, functional ability - along with increases in hospitalizations, psychological distress, mortality and use of healthcare services $(9,12-14)$. Fortin and coworkers emphasized the need for research on multimorbidity with a specific focus on defining the population and exploring its consequences (15). Thus, to better manage the consequence of chronic diseases among the working population, the adverse impact of multimorbidity on occupational outcomes, such as long-term sickness absence (LTSA), needs to be thoroughly investigated.

Having a chronic disease can negatively affect labor market participation. Hence, a lower employment rate have been observed among people with a chronic disease compared with healthy individuals $(1,16)$. Workers with a chronic disease often experience difficulties in meeting physical and psychosocial work demands, which further challenges their capacity to participate in gainful employment (17). Consequently, having a chronic disease at work is often accompanied by an imbalance between work demands and individual resources. This scenario may further influence work participation and overall working life. The concept of work ability reflects this balance between the capacity of the worker and work demands $(18,19)$. Impaired work ability has been associated with chronic disease, loss of productivity, sickness absence, early retirement and all-cause mortality (20-24). To secure work ability and thereby sustainable employability among workers with a chronic disease, it is crucial that the work environment is adjusted to fit the capabilities of the worker (25). For instance, work ability can be improved by adjusting the work demands to the health status and abilities of the worker and/or by increasing the workers physical and mental resources. However, it remains unknown to what extent poor work ability influence the consequence of one or multiple chronic diseases.

This study aims to determine the joint prospective association of number of chronic diseases and work ability with the risk of LTSA. We hypothesized that the number of chronic diseases was progressively associated with the risk of LTSA and that having poor work ability in combination with one or multiple chronic diseases would further increase this risk.

\section{Methods}

\section{Study design}

This study determines the prospective association between different chronic diseases and LTSA through merging of data from the Danish Work Environment Cohort Study (DWECS) and the Danish Register for Evaluation of Marginalization (DREAM). Further, we estimate the risk of

LTSA in relation to number of chronic diseases combined with either good or poor work ability.

\section{Participants and setting}

We used data from the 2010 round of the DWECS (26), which consists of a survey assessing work environment and health in the general working population of Denmark and has been repeated every fifth year since 1990. The questions on chronic diseases and work ability are specified below. A total of 10427 currently employed wage earners were included in the present study. The exact number of participants included in each analysis varies since not all participants completed all the survey questions. Baseline characteristics of the study population are shown in table 1 .

\section{Ethical approval}

The study was notified to and registered with the Danish Data Protection Agency (journal number: 2007-540059). According to Danish law, questionnaire-based and register-based studies do not need approval from ethical and scientific committees, nor do they need informed consent $(27,28)$. All data were de-identified and analyzed anonymously.

Table 1. Demographics, health and work-related characteristics of the participants. [SD=standard deviation.]

\begin{tabular}{|c|c|c|c|c|}
\hline & $\mathrm{N}$ & Mean & SD & $\%$ \\
\hline Age (years) & 10427 & 43.5 & 11.7 & \\
\hline Men & 4762 & & & 45.7 \\
\hline Women & 5665 & & & 54.3 \\
\hline \multicolumn{5}{|l|}{ Smoking } \\
\hline Yes & 2356 & & & 23.2 \\
\hline Ex-smoker & 2916 & & & 28.7 \\
\hline No, never & 4897 & & & 48.2 \\
\hline \multicolumn{5}{|c|}{ Physical activity during leisure } \\
\hline Low & 1365 & & & 13.4 \\
\hline Moderate & 6853 & & & 67.5 \\
\hline High & 1938 & & & 19.1 \\
\hline BMI $\left(\mathrm{kg} / \mathrm{m}^{2}\right)$ & 10095 & 25.4 & 4.4 & \\
\hline \multicolumn{5}{|c|}{ Psychosocial work factors $(0-100)$} \\
\hline Emotional demands & 10154 & 44.6 & 25.1 & \\
\hline Influence at work & 10085 & 67.4 & 24.0 & \\
\hline Support from colleagues & 9473 & 73.1 & 21.5 & \\
\hline Support from leader & 9710 & 69.7 & 25.8 & \\
\hline \multicolumn{5}{|c|}{ Long-term sickness at baseline } \\
\hline No & 9544 & & & 91.5 \\
\hline Yes & 883 & & & 8.5 \\
\hline \multicolumn{5}{|l|}{ Number of chronic diseases } \\
\hline 0 & 4413 & & & 43.2 \\
\hline 1 & 3318 & & & 32.5 \\
\hline 2 & 1612 & & & 15.8 \\
\hline$\geq 3$ & 877 & & & 8.6 \\
\hline \multicolumn{5}{|c|}{ Work ability (physical demands) } \\
\hline Good & 9429 & & & 93.3 \\
\hline Poor & 682 & & & 6.7 \\
\hline \multicolumn{5}{|c|}{ Work ability (mental demands) } \\
\hline Good & 9426 & & & 93.3 \\
\hline Poor & 680 & & & 6.7 \\
\hline
\end{tabular}




\section{Predictor variables}

Chronic disease. Chronic disease was based on the following question, "Have you ever been informed by a physician that you have or have had one or more of the following conditions?" with the response options being "yes" or "no, never" to the following diseases: Depression, asthma, diabetes (all types), cardiovascular disease, cancer, impaired hearing, eczema, back disorders, or other conditions (29).

Work ability. Work ability was assessed in relation to physical and mental demands of the job by two singleitem questions from the Work Ability Index questionnaire (30): (i) "How do you rate your current work ability with respect to the physical demands of your work?" (ii) "How do you rate your current work ability with respect to the mental demands of your work?". Respondents were asked to reply on a 5-point scale: "excellent", "very good", "good", "fair" or "poor". Subsequently, these responses were dichotomized into good (excellent, very good and good) and poor (fair and poor) work ability to obtain more statistical power.

\section{Outcome variable}

The information on LTSA used in the present study was derived from DREAM and linked to the DWECS via the unique personal identification number which is given to all Danish citizens at birth. DREAM contains information on all transfer payments (including sickness absence compensation, employment, early retirement, government education, disability benefits etc) among other basic personal data for all Danish residents on a weekly basis. DREAM has high reliability, since all transfer payments are systematically recorded in the register and employers have a financial incentive to report sick leave as they can apply for compensation of employee sickness absence costs after 30 days of sick leave (31). LTSA was defined as having registered $\geq 6$ consecutive weeks in DREAM during the 2-year follow-up period (2011-2012).

\section{Control variables}

Control variables included age, gender, body mass index (BMI), smoking status ("no, never", "ex-smoker", and "yes"), job group (86 different job groups), physical activity during leisure (described in detail below), psychosocial work environment (described in detail below), and previous LTSA. Previous LTSA was derived from the DREAM register and defined as $\geq 1$ episode of LTSA ( $\geq 6$ consecutive weeks) over the preceding two years prior to baseline.

As previously described by Andersen et al (32), physical activity during leisure was measured by the following question: "How much time have you spent on each of the following leisure-time activities during the last year (including commuting to and from work)?" (i) "Walking, biking or other low-intensity exercise, where you do not get short of breath and do not begin to sweat (eg, Sunday walks or low-intensity gardening)?"; (ii) "Exercise training, heavy gardening, or higher intensity walking/biking, where you sweat and get short of breath?"; and (iii) "Strenuous exercise training or competitive sports?" Response categories for each sub-question were: $>4,2-4,<2$ hours/week or "I do not perform this activity". Low physical activity was defined as performing $<4$ hours of low-intensity physical activity per week and not performing moderateintensity and high-intensity activities at all. Moderate physical activity was defined as performing $>4$ hours of low-intensity physical activity per week or moderate or high-intensity for $<4$ hours/week. High physical activity was defined as performing moderate or high activity for $>4$ hours/week or a combination of moderate and high activity for 2-4 hours/week $(32,33)$.

The psychosocial work environment was measured by four dimensions from the Copenhagen Psychosocial Questionnaire (COPSOQ) - each dimension included a number of questions (34). Specifically, the psychosocial work environment dimensions were influence at work, emotional demands, support from colleagues, and support from leaders.

\section{Statistical analysis}

Using the PROC PHREG procedure on SAS version 9.4 (SAS Institute, Cary, NC, USA), the Cox proportional hazard model was used for modelling the probability of LTSA ( $\geq 6$ weeks) during the 2-year follow-up period. Specifically, we evaluated the causespecific hazard of an LTSA event by a competing risk approach, where we applied the standard Cox-regression for LTSA and censored for all events of permanent labor market drop-out based on the DREAM register within the follow-up period (ie, statutory retirement, early retirement, disability pension, immigration, or death). Because this was a register-based study, ie, not dependent on questionnaire drop-outs or the like, individuals could only leave the study in case of permanent dropout of the labor market, immigration or death (ie, the censoring variables). Thus, individuals were censored either at the end of the 2-year follow-up or when one of the competing events occurred (survival time), whichever came first. When individuals had an onset of LTSA within the follow-up period, the survival times were non-censored and referred to as event times. The estimation method was maximum likelihood and the results are reported as cause specific hazard ratios (HR) with $95 \%$ confidence intervals $(95 \% \mathrm{CI})$. 


\section{Results}

Of the 10427 participants, 3318 (32.5\%), 1612 (15.8\%) and $877(8.6 \%)$ participants experienced 1,2 or 3 or more chronic diseases, respectively (table 1). Further, $682(6.7 \%)$ and $680(6.7 \%)$ participants experienced poor work ability in relation to the physical and mental demands of their work, respectively.

Table 2 shows the absolute prevalence of LTSA in the follow-up period for the participants in each subgroup. Among those with no chronic diseases and good work ability [either physical (PWA) or mental (MWA)] $<6 \%$ experienced LTSA in the follow-up period. Of those with $\geq 3$ chronic diseases, the proportion of respondents with LTSA in the follow-up period were $15.5 \%$ when having good physical work ability (PWA) and $31.2 \%$ when having poor PWA. Of those having both depression and back disorders in combination with good PWA, 16.3\% experienced $\geq 1$ episode of LTSA in the follow-up period, whereas this was the case for $41.7 \%$ of those with the same disease status and poor PWA.

Table 3 shows the prevalence of each chronic disease as well as the prospective associations between different chronic diseases and risk of LTSA among the general working population. In the fully adjusted model 2 , depression, cancer, back disorders and other conditions increased the risk for LTSA by $62 \%, 48 \%, 41 \%$ and $27 \%$, respectively.

Table 4 shows prospective associations between number of chronic diseases combined with poor or good work ability and risk of LTSA. The fully adjusted model 2 shows that the number of chronic diseases is progressively associated with the risk of LTSA. Having 1, 2 or $\geq 3$ chronic diseases in combination with poor PWA or MWA increased the risk for LTSA compared to having the same number of chronic diseases but good work ability (HR 1.56-3.69). For instance, the risk estimate increased from 1.18 with one chronic disease and good PWA to 2.37 with one chronic disease and poor PWA. Further, the risk estimate increased from 1.95 with $\geq 3$ chronic diseases and good PWA to 3.60 with $\geq 3$ chronic diseases and poor PWA. Similar results were observed for number of chronic diseases and good versus poor MWA. Overall, the joint association of chronic disease and work ability with LTSA appears to be additive.

Table 5 shows prospective associations between depression and/or back disorders combined with good or poor work ability and risk of LTSA. The risk estimate for LTSA was 2.36 when having either depression or a back disorder in combination with poor PWA and 1.57 when having either depression or back disorders in combination with good PWA. When having both depression and back disorders in combination with poor PWA, the risk estimate was 4.32 , whereas it was 1.77 when
Table 2. Absolute prevalence of LTSA (in percent) in the follow-up period for individuals in each subgroup. [WA=work ability].

\begin{tabular}{|c|c|c|c|c|}
\hline & \multicolumn{2}{|c|}{ Physical WA } & \multicolumn{2}{|c|}{ Mental WA } \\
\hline & Good & Poor & Good & Poor \\
\hline \multicolumn{5}{|l|}{ Number of chronic diseases } \\
\hline 0 & 5.8 & 14.3 & 5.7 & 14.7 \\
\hline 1 & 8.2 & 23.1 & 8.6 & 15.5 \\
\hline 2 & 11.7 & 23.8 & 12.2 & 21.4 \\
\hline$\geq 3$ & 15.3 & 31.2 & 16.6 & 30.0 \\
\hline \multicolumn{5}{|l|}{ Status } \\
\hline No depression or back disease & 6.6 & 18.9 & 6.7 & 16.3 \\
\hline Either depression or back disorder & 12.7 & 24.8 & 13.5 & 20.6 \\
\hline Both depression and back disorder & 16.3 & 41.7 & 19.4 & 33.3 \\
\hline
\end{tabular}

Table 3. Risk of long-term sickness absence ( $\geq 6$ weeks) during 2-year follow-up in relation to the different chronic diseases. All models were mutually adjusted for other types of chronic diseases, eg, hazard ratios (HR) for depression is adjusted for 8 other chronic diseases. [ $95 \% \mathrm{Cl}=95 \%$ confidence interval.]

\begin{tabular}{|c|c|c|c|c|c|c|}
\hline & \multirow[t]{2}{*}{$\mathrm{N}$} & \multirow[t]{2}{*}{$\%$} & \multicolumn{2}{|c|}{ Model $1{ }^{\mathrm{a}}$} & \multicolumn{2}{|c|}{ Model $2 \mathrm{~b}$} \\
\hline & & & $\mathrm{HR}$ & $95 \% \mathrm{Cl}$ & $\mathrm{HR}$ & $95 \% \mathrm{Cl}$ \\
\hline Depression & 1272 & 12.5 & 1.93 & $1.66-2.26$ & 1.62 & $1.36-1.94$ \\
\hline Asthma & 1007 & 9.9 & 1.01 & 0.82 & 0.94 & 0.74 \\
\hline Diabetes & 316 & 3.1 & 1.32 & $0.97-$ & 1.28 & $0.90-1.83$ \\
\hline $\begin{array}{l}\text { Cardiovascular } \\
\text { disease }\end{array}$ & 489 & 4.8 & 1.13 & $0.87-1.46$ & 1.01 & $0.74-1.36$ \\
\hline Canc & & & 1.60 & $1.22-$ & 1.48 & \\
\hline ed hearing & 1038 & 10.2 & 1.07 & 0.88 & 1.04 & 0.82 \\
\hline Ecze & 2001 & 19.6 & 1.06 & $0.90-$ & 1.11 & $0.93-1.33$ \\
\hline Back disord & 1650 & 16.2 & 1.58 & $1.35-1.84$ & 1.41 & $1.18-1.68$ \\
\hline Other & 1448 & 14.2 & 1.44 & $1.23-1.69$ & 1.27 & $1.06-1.52$ \\
\hline
\end{tabular}

${ }^{a}$ Adjusted for age and gender.

b Model 1 + job group, psychosocial work environment (influence at work, emotional demands, support from colleagues, support from leader), lifestyle (smoking, leisure physical activity, body mass index), and previous long-term sickness absence.

having both conditions but good PWA. Similar results were observed for MWA and risk of LTSA. In general, having poor compared with good work ability and the same combination of chronic diseases (depression or back disorders) increased the risk for LTSA. Overall, the joint association of depression, back disorders and work ability with LTSA appears to be additive.

\section{Discussion}

The study shows that the joint effects of work ability and number of chronic diseases were associated with the risk of LTSA in the general working population. Specifically, the number of chronic diseases was progressively associated with the risk of LTSA, and good work ability counteracted to some extent this increased risk. Initiatives to improve or maintain work ability should be highly prioritized to secure sustainable employability 
Table 4. Risk of long-term sickness absence ( $\geq 6$ weeks) during 2 -year follow-up in relation to number of chronic diseases combined with poor/good work ability (WA). The categories of number of chronic diseases include all possible combinations (ie, participants belong to either 0, 1, 2, $\geq 3$ diseases). [PWA=physical WA; MWA=mental WA. $\mathrm{HR}=$ hazards ratio; $95 \% \mathrm{Cl}=95 \%$ confidence interval.]

\begin{tabular}{|c|c|c|c|c|c|c|}
\hline \multirow{2}{*}{$\begin{array}{l}\text { Number of } \\
\text { chronic diseases }\end{array}$} & \multirow[t]{2}{*}{$\mathrm{N}$} & \multirow[t]{2}{*}{$\%$} & \multicolumn{2}{|c|}{ Model $1^{\mathrm{a}}$} & \multicolumn{2}{|c|}{ Model $2{ }^{b}$} \\
\hline & & & $\mathrm{HR}$ & $95 \% \mathrm{Cl}$ & HR & $95 \% \mathrm{Cl}$ \\
\hline (good PWA) & 4201 & 41.9 & 1 & & 1 & \\
\hline (good PWA) & 3073 & 30.7 & 1.39 & $1.17-1.66$ & 1.18 & $0.97-1$ \\
\hline (good PWA) & 1397 & 13.9 & 1.98 & $1.63-2.42$ & 1.57 & $.20-1.8$ \\
\hline$\geq 3(\operatorname{good} P W A)$ & 686 & 6.8 & 2.53 & $2.01-3.19$ & 1.95 & $1.50-2.52$ \\
\hline 0 (poor PWA) & 119 & 1.2 & 2.66 & $1.62-4.34$ & 1.63 & $0.87-3.0$ \\
\hline 1 (poor PWA) & 195 & 1.9 & 3.92 & $2.85-5.40$ & 2.37 & $1.62-3.4$ \\
\hline 2 (poor PWA) & 185 & 1.9 & 4.22 & $3.06-5.83$ & 2.52 & $1.73-3.67$ \\
\hline$\geq 3$ (poor PWA) & 170 & 1.7 & 5.82 & $4.32-7.86$ & 3.60 & \\
\hline 0 (good MWA) & 4161 & 41.5 & 1 & & 1 & \\
\hline $1(\operatorname{good} M W A)$ & 3045 & 30.4 & 1.49 & $1.25-1.77$ & 1.27 & $1.04-1$ \\
\hline $2(\operatorname{good} M W A)$ & 1412 & 14.1 & 2.10 & $1.72-$ & 1.68 & 1.35 \\
\hline$\geq 3(\operatorname{good} M W A)$ & 734 & 7.3 & 2.80 & $2.24-3.49$ & 2.07 & $1.61-2.66$ \\
\hline 0 (poor MWA) & 163 & 1.6 & 2.72 & $1.79-4.14$ & 1.92 & $1.16-3.19$ \\
\hline 1 (poor MWA) & 219 & 2.2 & 2.69 & $1.87-3.85$ & 1.56 & $1.01-2.40$ \\
\hline 2 (poor MWA) & 168 & 1.7 & 3.91 & $2.75-5.55$ & 2.11 & \\
\hline$\geq 3$ (poor MWA) & 120 & 1.2 & 5.62 & $3.95-7.99$ & 3.69 & $2.41-5.65$ \\
\hline
\end{tabular}

${ }^{\mathrm{b}}$ Adjusted for age and gender.

${ }^{\mathrm{b}}$ Model $1+$ job group, psychosocial work environment (influence at work, emotional demands, support from colleagues, support from leader), lifestyle (smoking, leisure physical activity, body mass index) and previous long-term sickness absence.

among workers with one or more chronic diseases.

Of the eight specific chronic diseases included in the questionnaire only depression, cancer and back disorders were significant predictors for LTSA (table 3). The prevalence of depression and back disorders was relatively high, $12.5 \%$ and $16.2 \%$ respectively, whereas cancer had only been diagnosed among $3.2 \%$ of the general working population (table 2). This is in agreement with a previous study including $>160000$ Danes, reporting prevalence rates of $13.3 \%$ for back disorders and $2.6 \%$ for cancer (2). In opposition, studies using hospitalization registers to assess depression in Denmark suggest a prevalence of depression of 3-5\% of the Danish population (34), and according to the Danish medical statistics, $8.3 \%$ ( $>460$ 000 Danes) of the population was prescribed antidepressants in 2011 (35). These rates are lower than those presented in the present study, which may be related to different factors. First, the validity of using self-reports for measuring prevalence of depression can be questioned (using a single question on diagnosed depression by a doctor instead of a depressive symptom scale or medical registers). Second, the hospitalization register showing a prevalence of 3-5\% accounts only for those individuals who have been hospitalized due to their depression, ie, relatively serious cases, which may underestimate the number of all cases of depression. Thus, while self-reports of some diseases appears to be accurate, future studies could verify self-reports of depression for example by the use of medical records $(36,37)$.
Table 5. Risk of long-term sickness absence ( $\geq 6$ weeks) during 2-year follow-up in relation to depression and/or back disorders combined with poor/good work ability (WA). All the models were mutually adjusted for the 7 types of chronic diseases other than depression and back disease. [PWA=physical WA); MWA=mental WA; HR=hazards ratio; $95 \% \mathrm{Cl}=95 \%$ confidence interval.]

\begin{tabular}{|c|c|c|c|c|c|c|}
\hline \multirow{2}{*}{$\begin{array}{l}\text { Presence of depres- } \\
\text { sion or back disorder }\end{array}$} & \multirow[t]{2}{*}{$\mathrm{N}$} & \multirow[t]{2}{*}{$\%$} & \multicolumn{2}{|c|}{ Model $1^{\mathrm{a}}$} & \multicolumn{2}{|c|}{ Model $2^{b}$} \\
\hline & & & $\mathrm{HR}$ & $95 \% \mathrm{Cl}$ & $\mathrm{HR}$ & $95 \% \mathrm{Cl}$ \\
\hline No (good PWA) & 7144 & 71.3 & 1 & & 1 & \\
\hline Either (good PWA) & 1972 & 19.7 & 1.84 & $1.57-2.15$ & 1.57 & $1.32-1.88$ \\
\hline Both (good PWA) & 240 & 2.4 & 2.23 & $1.60-3.10$ & 1.77 & $1.21-2.58$ \\
\hline No (poor PWA) & 318 & 3.2 & 2.71 & $2.06-3.56$ & 1.87 & $1.34-2.61$ \\
\hline Either (poor PWA) & 278 & 2.8 & 3.53 & $2.72-4.58$ & 2.36 & $1.74-3.20$ \\
\hline Both (poor PWA) & 72 & 0.7 & 6.15 & $4.19-9.05$ & 4.32 & $2.72-6.86$ \\
\hline No (good MWA) & 7099 & 70.9 & 1 & & 1 & \\
\hline WA) & 2004 & 20.0 & 1.90 & $1.63-$ & 1.65 & $1.39-1.96$ \\
\hline Both & 248 & 2.5 & 2.53 & $1.87-3.43$ & 1.98 & $1.40-2.82$ \\
\hline No (poor MWA) & 363 & 3.6 & 2.40 & $1.83-3.15$ & 1.75 & $1.25-2.44$ \\
\hline Either (poor MWA) & 243 & 2.4 & 2.91 & $2.17-3.91$ & 1.79 & $1.24-2.57$ \\
\hline Both (poor MWA) & 63 & 0.6 & 4.79 & $3.06-7.48$ & 3.41 & $2.00-5.83$ \\
\hline
\end{tabular}

${ }^{a}$ Adjusted for age and gender.

${ }^{\mathrm{b}}$ Model $1+$ job group, psychosocial work environment (influence at work, emotional demands, support from colleagues, support from leader), lifestyle (smoking, leisure physical activity, body mass index), and previous long-term sickness absence.

Both diabetes and cardiovascular disease (CVD) are two of the greatest health challenges worldwide. In the present study, these diseases were present in $<5 \%$ of the workers, but they did not influence the risk estimates for LTSA significantly (table 3 ). Previous studies have reported increased sickness absence rates in people with diabetes compared with diabetes-free subjects $(38,39)$, and CVD has been shown to be responsible for more deaths worldwide than any other condition (40). It could be speculated, that the results of the present study are influenced by a healthy workers effect, suggesting that those with a severe CVD or diabetes might already have left the labor market or shifted to a job with a better match between work demands and individual capacity. Altogether, this could lower the risk estimates for the remaining workers with chronic disease and poor work ability, and our estimates may therefore be conservative. Another possibility is that the presence of these diseases occurred some years ago and that the disease is now under control, eg, blood sugar levels are typically well controlled in Denmark after a diagnosis has been made.

Asthma was present in $9.9 \%$ of the respondents, but it did not seem to increase the risk for LTSA. Thus it could be speculated that, for most asthmatic persons, the disease can be controlled by proper treatment and will therefore not affect work participation.

In the present study eczema and hearing loss (ie, impaired hearing) were very common in the general working population, but they did not influence LTSA to any significant extent. Hence it seems that these conditions in general, do not decrease work ability to an extent that require days away from work. 
Most research on multimorbidity has been conducted on either specific patient groups or on older individuals, whereas only few studies on the general workforce have focused on the coexistence of several chronic diseases. Casimirri and co-workers found an association between sickness absence days and the presence of $\geq 2$ chronic diseases in a cross-sectional study among 514 sicklisted and not sick-listed Italian workers (41). Likewise, Ubalde-Lopez found that the greater the number of health conditions, the higher the risk of sickness absence in a cross sectional study of 72370 Spanish workers (7). Our study elaborates on these previous findings by showing that the number of chronic diseases is progressively associated with the risk of LTSA. In addition, we observed that $15.8 \%$ and $8.6 \%$ of the participants had 2 , or $\geq 3$ chronic diseases, respectively. This highlights the need for initiatives targeting rehabilitation and prevention of multimorbidity among the general working population.

The balance between capacity of the worker and work demands, reflected by work ability, has shown to be impaired among individuals with a chronic disease $(20,21,25)$. For instance, Koolhaas et al found that ageing workers ( $\geq 45$ years) with a chronic disease experienced lower work ability and suggested that these workers might benefit most from a policy focusing on enhancing associated variables such as psychosocial factors and perceived health status (25). However, to our knowledge, no previous study has investigated whether good MWA and PWA in combination with chronic disease could reduce the consequence of the condition (ie, lower the risk for LTSA). In the present study, we observed that having $\geq 1$ chronic diseases in combination with either poor PWA or MWA increased the risk of LTSA compared with having the same number of chronic diseases but good work ability (table 4). Specifically, the analysis presented in table 4 shows the additional risk of having poor versus good work ability, underlining the rehabilitation potential for improving work ability among workers with $\geq 1$ chronic diseases. Overall taken, it seems that good work ability protects against the consequence of having $\geq 1$ chronic diseases by lowering the risk of transition into LTSA. It should be remembered that poor MWA or PWA in combination with $\geq 1$ chronic diseases was present for only a small percentage of the participants, but for those with poor work ability and a chronic disease, the consequences seem to be substantial. This is further acknowledged in the raw percentages of table 2, showing that $>30 \%$ of those with $\geq 3$ chronic diseases and poor work ability (physical or mental) had $\geq 1$ episode of LTSA in the follow-up period.

The high prevalence of depression and back disorders in combination with their high prospective association with LTSA (table 3) led to the analysis illustrated in table 5. There we estimated the joint association of depression and/or back disorders and work ability with the risk of LTSA. It is not surprising that specifically depression and back disorders are both prevalent and caused the highest risk of LTSA. Both depression and low-back pain are listed as the global leading causes of years lived with disability (42) and the coexistence of depression and low-back pain have been reported in numerous studies (43-45). Lloyd and coworkers showed that individuals with depression comorbid with a musculoskeletal disorder (MSD) were at higher labor force disadvantage than people with MSD alone, and that having a comorbid disease such as depression amplifies the negative impact of having a single MSD on labor force activity (46). Likewise, Waghorn and coworkers showed that back problems and comorbid depression led to the highest negative impact on employment and work participation $(46,47)$. In the present study, we found that the probability of LTSA was higher when having both depression and back disorders in combination with poor PWA or MWA (HR 4.32 and 3.41, respectively), compared with having both conditions but good PWA or MWA (HR 1.77 and 1.98, respectively). This consequence is further acknowledged by the fact that $>40 \%$ of those with poor PWA in combination with both disorders had $\geq 1$ episode of LTSA in the follow-up period (table 2). Overall taken, it seems that the consequences of poor PWA are more pronounced than those for poor MWA. The present results highlight the need for additional treatment for workers with comorbid back disorders and depression. Improving PWA and MWA seems to be a key treatment goal which should be an integrated part of occupational rehabilitation for workers with multimorbidity.

Even though many previous studies have reported no or only minor effects of interventions aiming to improve work ability, several recent studies shows that physical exercise at the workplace have the ability to influence work ability $(48,49)$. For instance, ten weeks of strength training improved work ability in relation to physical and mental demands of the job - ie, the same questions as used in the present study - in both slaughterhouse workers with chronic pain and work disability and in healthcare workers $(48,49)$. Future research should investigate the effect of interventions aimed at increasing physical and mental capacity (eg, by physical activity and cognitive training), and reducing the physical and mental demands of the job (eg, by adjusting the work demands to the capacity of the workers), in workers with multiple chronic diseases and poor work ability. Overall taken, work ability seems to be a factor that can be enhanced (either by adjusting the work demands and/or by increasing physical and mental resources) and workplace initiatives to improve or maintain work ability should be highly prioritized to secure sustainable employability among workers with chronic diseases. 


\section{Strength and limitations}

In the present study we adjusted for previous LTSA in model 2, which changes the outcome of the analyses from future sickness absence to future sickness absence that is independent of previous sickness absence, corresponding to the change in LTSA from baseline to followup (50). The results should be interpreted with this in mind. Having a chronic disease was self-reported and could therefore have been influenced by recall or reporting bias. However, the questionnaire specifically stated that the chronic disease should have been diagnosed by a physician, which likely reduces reporting bias. A limitation is that we did not ask about when the disease was diagnosed, thus for some diseases the lack of association with LTSA may be due to proper control of the respective disease. In the present study we did not ask about 'current' chronic diseases, but 'ever' having a chronic disease. Because chronic diseases may not necessarily be for life, this may partially explain the relatively high percentage of at least one chronic disease (56.8\%). At the same time this may be a strength as it reflects the overall impact of a certain disease on LTSA seen in the long perspective. Further, the proportion of participants with a specific chronic disease (e.g. back disorders and cancer) were comparable with previous studies including a larger sample of the Danish adult population for most of the chronic diseases $(2,6)$, which strengthens the validity of the self-reports. However, specifically for depression the proportion of self-reports were higher than those previously determined based on registers of hospitalization or medicine. The categorization of chronic diseases makes it difficult to know the specific diagnosis for back disorders, CVD, and other diseases. Likely, back disorders diagnosed by a physician refers to diagnosis such as disc prolapse, degenerative disc disease and chronic low-back pain. However, the design of the study makes it impossible to conclude on the specific diagnosis. In addition, both the prevalence and the consequence (ie, risk for LTSA) of "other chronic disease" was high in the present study, but the specific diagnoses included in this category remains unknown. In the present analyses, work ability was dichotomized into "good" (excellent, very good and good) or "poor" (fair and poor) to obtain more statistical power. As this was not based on clinical relevance, one should be aware of this in the interpretation of the results - especially regarding the practical implications of the study. However, the cut-off was inspired by the classification of work ability by Tuomi and coworkers (30), who have argued that the objective of initiatives for workers with poor to moderate work ability is to improve or restore work ability, whereas the objective for workers with good to excellent work ability is to support or maintain work ability. A strength of the study is the use of infor- mation on sickness absence derived from the DREAM register. The DREAM register has high validity as employers have an economic incentive to report sickness absence since employers can apply for compensation of employee sickness absence costs after 30 days of sickness absence. This inherently eliminates any reporting or recall bias. Finally, the use of a representative sample of the general working population in Denmark increases the generalizability of the study.

In conclusion, this prospective cohort study shows that the joint effect of work ability and number of chronic diseases substantially affects the risk of LTSA in the general working population. The number of chronic diseases was progressively associated with the risk of LTSA and good work ability counteracted to some extent this increased risk. Overall, the joint association of chronic disease and work ability with LTSA appears to be additive. The study suggests that initiatives to improve or maintain work ability should be highly prioritized to secure sustainable employability among workers with chronic diseases, especially among those with a comorbidity of back disorders and depression.

\section{Acknowledgements}

The authors are grateful to colleagues Elsa Bach and Ebbe Villadsen at NRCWE for valuable discussions and assistance with access to data from the Danish Work Environment Cohort Study.

This research received funding from the Danish Government (Finansloven). The authors declare no conflicts of interest.

\section{References}

1. Vooijs M, Leensen MCJ, Hoving JL, Wind H, Frings-Dresen MHW. Interventions to enhance work participation of workers with a chronic disease: a systematic review of reviews. Occup Environ Med. 2015 Nov;72(11):820-6. https://doi. org/10.1136/oemed-2015-103062.

2. Sundhedsstyrelsen [The Danish Health Authority]. Danskernes Sundhed - Den Nationale Sundhedsprofil 2013 [The Danish Health - The National Health Profile in 2013]. 2014.

3. Leijten FRM, de Wind A, van den Heuvel SG, Ybema JF, van der Beek AJ, Robroek SJW, et al. The influence of chronic health problems and work-related factors on loss of paid employment among older workers. J Epidemiol Community Health. 2015 Nov;69(11):1058-65. https://doi.org/10.1136/ jech-2015-205719.

4. Iwan A, World Health Organization. Global status report on noncommunicable diseases 2010. Geneva, Switzerland: World 
Health Organization; 2011.

5. Busse R, European Observatory on Health Systems and Policies, editors. Tackling chronic disease in Europe: Strategies, interventions and challenges. Copenhagen: World Health Organization, Regional Office for Europe; 2010.

6. Sundhedsstyrelsen [The Danish Health Authority]. Den nationale sundhedsprofil 2010 - Hvordan har du det? [The National Health Profile in 2010 - How are you?]. 2011.

7. Ubalde-Lopez M, Delclos GL, Benavides FG, Calvo-Bonacho E, Gimeno D. Measuring multimorbidity in a working population: the effect on incident sickness absence. Int Arch Occup Environ Health. 2016 May;89(4):667-78. https://doi. org/10.1007/s00420-015-1104-4.

8. van den Akker M, Buntinx F, Metsemakers JF, Roos S, Knottnerus JA. Multimorbidity in general practice: prevalence, incidence, and determinants of co-occurring chronic and recurrent diseases. J Clin Epidemiol. 1998 May;51(5):367-75. https://doi.org/10.1016/S0895-4356(97)00306-5.

9. Caughey GE, Vitry AI, Gilbert AL, Roughead EE. Prevalence of comorbidity of chronic diseases in Australia. BMC Public Health. 2008;8(1):221. https://doi.org/10.1186/1471-2458-8221.

10. Australian Bureau of Statistics. National Health Survey: Summary of Results 2004-2005. Canberra: Commonwealth of Australia; 2006.

11. Australian Institute of Health and Welfare (AIHW). Chronic diseases and associated risk factors in Australia, 2006. Canberra, ACT; 2006.

12. Wolff JL, Starfield B, Anderson G. Prevalence, expenditures, and complications of multiple chronic conditions in the elderly. Arch Intern Med. 2002 Nov 11;162(20):2269-76. https://doi. org/10.1001/archinte.162.20.2269.

13. Gijsen R, Hoeymans N, Schellevis FG, Ruwaard D, Satariano WA, van den Bos GA. Causes and consequences of comorbidity: a review. J Clin Epidemiol. 2001 Jul;54(7):66174. https://doi.org/10.1016/S0895-4356(00)00363-2.

14. Fortin M, Bravo G, Hudon C, Lapointe L, Almirall J, Dubois M-F, et al. Relationship between multimorbidity and healthrelated quality of life of patients in primary care. Qual Life Res. 2006 Feb;15(1):83-91. https://doi.org/10.1007/s11136005-8661-z.

15. Fortin M, Soubhi H, Hudon C, Bayliss EA, Akker M v. d. Multimorbidity's many challenges. BMJ. 2007 May 19;334(7602):1016-7. https://doi.org/10.1136/ bmj.39201.463819.2C.

16. Maurits E, Rijken M, Friele R. Kennissynthese "Chronisch ziek en werk": Arbeidsparticipatie door mensen met een chronische ziekte of lichamelijke beperking [Knowledge Synthesis "Chronically ill and Work": Employment by people with a chronic illness or physical disability]. Utrecht, Holland: Nivel; 2013.

17. J. Lerner D, C. Amick III B, Malspeis S, H. Rogers W. A national survey of health-related work limitations among employed persons in the United States. Disabil Rehabil. 2000 Jan;22(5):225-32. https://doi. org/10.1080/096382800296791.
18. Ilmarinen J, Tuomi K. Past, Present and Future of Work Ability. People Work -Res Rep. J Hels Finl Finn Inst Occup Health. 2004;65:581-9.

19. Ilmarinen J. Work ability--a comprehensive concept for occupational health research and prevention. Scand J Work Environ Health. 2009 Jan;35(1):1-5. https://doi.org/10.5271/ sjweh.1304.

20. Tuomi K, Ilmarinen J, Eskelinen L, Järvinen E, Toikkanen J, Klockars M. Prevalence and incidence rates of diseases and work ability in different work categories of municipal occupations. Scand J Work Environ Health. 1991;17 Suppl $1: 67-74$

21. Alavinia S, de Boer AGEM, van Duivenbooden JC, FringsDresen MHW, Burdorf A. Determinants of work ability and its predictive value for disability. Occup Med Oxf Engl. 2009 Jan;59(1):32-7. https://doi.org/10.1093/occmed/kqn148.

22. Seitsamo J, Martikainen R. Work ability and all cause mortality; A 25-year longitudinal study among Finnish municipal workers. Promotion of workability towards prodctive ageing London: Taylor and Francis Group; 2009. p. $101-4$.

23. Neupane S, Miranda H, Virtanen P, Siukola A, Nygård C-H. Multi-site pain and work ability among an industrial population. Occup Med Oxf Engl. 2011 Dec;61(8):563-9. https://doi.org/10.1093/occmed/kqr130.

24. Vänni K, Virtanen P, Luukkaala T, Nygård C-H. Relationship between perceived work ability and productivity loss. Int. J Occup Saf Ergon JOSE. 2012;18(3):299-309.

25. Koolhaas W, van der Klink JJL, de Boer MR, Groothoff JW, Brouwer S. Chronic health conditions and work ability in the ageing workforce: the impact of work conditions, psychosocial factors and perceived health. Int Arch Occup Environ Health [Internet]. 2013 May 16 [cited 2016 Apr 29]; Available from: http://link.springer.com/10.1007/s00420-013-0882-9.

26. Burr H, Bjorner JB, Kristensen TS, Tüchsen F, Bach E. Trends in the Danish work environment in 1990-2000 and their associations with labor-force changes. Scand J Work Environ Health. 2003 Aug;29(4):270-9. https://doi.org/10.5271/ sjweh.731.

27. The Danish Data Protection Agency. The Danish Data Protection Agency. Standard terms for research projects - AUTHORISATION to process personal data [Internet]. Copenhagen: The Danish Data Protection Agency; 2008. Available from: http://www.datatilsynet.dk/erhverv/forskereog-medicinalfirmaer/standard-terms-for-researchprojects/.

28. Committee System on Biomedical Research Ethics. Guidelines about Notification [Internet]. Copenhagen: Committee System on Biomedical Research Ethics; 2011. Available from: http:// www.dnvk.dk/English/guidelinesaboutnotification.aspx.

29. Calatayud J, Jakobsen MD, Sundstrup E, Casa-a J, Andersen LL. Dose-response association between leisure time physical activity and work ability: Cross-sectional study among 3000 workers. Scand J Public Health. 2015 Dec;43(8):819-24. https://doi.org/10.1177/1403494815600312.

30. Tuomi K, Ilmarinen J, Jahkola A, Katajarinne L, Tulkki A. 
Work Ability Index. $2^{\text {nd }}$ revised ed. Helsinki: Finnish Institute of Occupational Health; 1998.

31. Lund T, Kivimäki M, Labriola M, Villadsen E, Christensen $\mathrm{KB}$. Using administrative sickness absence data as a marker of future disability pension: the prospective DREAM study of Danish private sector employees. Occup Environ Med. 2008 Jan;65(1):28-31. https://doi.org/10.1136/oem.2006.031393.

32. Andersen LL, Fallentin N, Thorsen SV, Holtermann A. Physical workload and risk of long-term sickness absence in the general working population and among blue-collar workers: prospective cohort study with register follow-up. Occup Environ Med. 2016 Apr;73(4):246-53. https://doi. org/10.1136/oemed-2015-103314

33. Sundstrup E, Jakobsen MD, Thorsen SV, Andersen LL. Regular use of medication for musculoskeletal pain and risk of long-term sickness absence: A prospective cohort study among the general working population. Eur J Pain. 2016. [Epub ahead of print] https://doi.org/10.1002/ejp.932.

34. Pejtersen JH, Kristensen TS, Borg V, Bjorner JB. The second version of the Copenhagen Psychosocial Questionnaire." Scand J Public Health. 2010;38(3):8-24.

35. Vilhelmsson A. Depression and antidepressants: a nordic perspective. Front Public Health. 2013;1:30. https://doi. org/10.3389/fpubh.2013.00030.

36. Bergmann MM, Byers T, Freedman DS, Mokdad A. Validity of self-reported diagnoses leading to hospitalization: a comparison of self-reports with hospital records in a prospective study of American adults. Am J Epidemiol. 1998 May 15;147(10):969-77. https://doi.org/10.1093/ oxfordjournals.aje.a009387.

37. Barr ELM, Tonkin AM, Welborn TA, Shaw JE. Validity of self-reported cardiovascular disease events in comparison to medical record adjudication and a statewide hospital morbidity database: the AusDiab study. Intern Med J. 2009 Jan;39(1):4953. https://doi.org/10.1111/j.1445-5994.2008.01864.x.

38. De Backer G, Leynen F, De Bacquer D, Clays E, Moreau M, Kornitzer M. Diabetes mellitus in middle-aged people is associated with increased sick leave: the BELSTRESS study. Int J Occup Environ Health. 2006 Mar;12(1):28-34. https:// doi.org/10.1179/oeh.2006.12.1.28.

39. Kivimäki M, Vahtera J, Pentti J, Virtanen M, Elovainio $\mathrm{M}$, Hemingway $\mathrm{H}$. Increased sickness absence in diabetic employees: what is the role of co-morbid conditions? Diabet Med J Br Diabet Assoc. 2007 Sep;24(9):1043-8. https://doi. org/10.1111/j.1464-5491.2007.02216.x.

40. Peterson AM, McGhan WF. Pharmacoeconomic impact of non-compliance with statins. PharmacoEconomics. 2005;23(1):13-25. https://doi.org/10.2165/00019053200523010-00002.
41. Casimirri E, Vaccari A, Schito M, Bonci M, Stendardo M, Stefanati A, et al. Chronic diseases are strongly associated with sickness absences in a sample of Italian public employees. Int J Occup Med Environ Health. 2014 Jun;27(3):343-54. https:// doi.org/10.2478/s13382-014-0256-x.

42. Global, regional, and national incidence, prevalence, and years lived with disability for 301 acute and chronic diseases and injuries in 188 countries, 1990-2013: a systematic analysis for the Global Burden of Disease Study 2013. The Lancet. 2015 Aug;386(9995):743-800. https://doi.org/10.1016/S01406736(15)60692-4.

43. Pengel LHM. Acute low back pain: systematic review of its prognosis. BMJ. 2003 Aug 9;327(7410):323-30. https://doi. org/10.1136/bmj.327.7410.323.

44. Sullivan MJL, Reesor K, Mikail S, Fisher R. The treatment of depression in chronic low back pain: review and recommendations: Pain. 1992 Jul;50(1):5-13. https://doi. org/10.1016/0304-3959(92)90107-M.

45. Pinheiro MB, Ferreira ML, Refshauge K, Maher CG, Ordoana JR, Andrade TB, et al. Symptoms of depression as a prognostic factor for low back pain: a systematic review. Spine J. 2016 Jan;16(1):105-16. https://doi.org/10.1016/j. spinee.2015.10.037.

46. Lloyd C, Waghorn G, McHugh C. Musculoskeletal disorders and comorbid depression: Implications for practice. Aust Occup Ther J. 2008 Mar;55(1):23-9. https://doi.org/10.1111/ j.1440-1630.2006.00624.x.

47. Waghorn G, Chant D, Lloyd C. Labor force activity among Australians with musculoskeletal disorders comorbid with depression and anxiety disorders. J Occup Rehabil. 2006 Jun;16(2):235-46. https://doi.org/10.1007/s10926-006-9018-3.

48. Sundstrup E, Jakobsen MD, Brandt M, Jay K, Persson $\mathrm{R}$, Aagaard $\mathrm{P}$, et al. Workplace strength training prevents deterioration of work ability among workers with chronic pain and work disability: a randomized controlled trial. Scand J Work Environ Health. 2014 May 1;40(3):244-51. https://doi. org/10.5271/sjweh.3419.

49. Jakobsen MD, Sundstrup E, Brandt M, Jay K, Aagaard P, Andersen LL. Physical exercise at the workplace prevents deterioration of work ability among healthcare workers: cluster randomized controlled trial. BMC Public Health. 2015;15:1174. https://doi.org/10.1186/s12889-015-2448-0.

50. Rugulies R, Christensen KB, Borritz M, Villadsen E, Bültmann U, Kristensen TS. The contribution of the psychosocial work environment to sickness absence in human service workers: Results of a 3-year follow-up study. Work Stress. 2007 Oct;21(4):293-311. https://doi. org/10.1080/02678370701747549.

Received for publication: 26 October 2016 